\title{
Hepatic Portal Venous Gas and Anastomotic Leakage
}

\author{
Filippo Carannante, Gabriella Teresa Capolupo, Gianluca Mascianà, Marco Caricato \\ Colorectal Surgery Unit, Campus Bio-Medico University of Rome, Italy
}

To the editor:

We read with great interest the article titled, "Successful conservative management of hepatic portal venous gas due to anastomosis leakage after a sigmoidectomy," written by Hong et al. [1]. The authors affirm that they "were unable to find any cases of hepatic portal venous gas (HPVG) associated with anastomotic leak after a colon resection."

Last year, our group published a case report and literature review of HPVG [2]. In our case, "a computed tomography scan showed little perianastomotic collections with air-fluid levels and massive hepatic portal venous gas." Furthermore, in our literature review, we reported a paper that presented a case of HPVG with anastomosis leakage [3]. Other papers we reported presented cases of HPVG due to surgical complications, while not specifying which types [4-7].

We write this letter to specify that the HPVG condition could be associated with anastomotic leakage and the management of this surgical complication should also solve the portal venous gas problem.

\section{CONFLICT OF INTEREST}

No potential conflict of interest relevant to this article was reported.

\section{REFERENCES}

1. Hong I, Hong SW, Chang YG, Lee B, Lee WY, Ohe HJ, et al. Successful conservative management of hepatic portal venous gas due to anastomosis leakage after a sigmoidectomy. Ann Coloproctol 2019;35:282-4.

2. Capolupo GT, Mascianà G, Carannante $F$, Caricato M. Hepatic portal venous gas after colonoscopy: a case report and review. Int J Surg Case Rep 2018;51:54-7.

3. Li Z, Su Y, Wang X, Yan H, Sun M, Shu Z. Hepatic portal venous gas associated with colon cancer: a case report and literature review. Medicine (Baltimore) 2017;96:e9352.

4. Castren EE, Hakeem AR, Mahmood NS, Aryal K. Case of pneumatosis intestinalis and hepatic portal venous gas following a laparoscopic right hemicolectomy. BMJ Case Rep 2016;2016:bcr2016 214431.

5. Moser A, Stauffer A, Wyss A, Schneider C, Essig M, Radke A. Conservative treatment of hepatic portal venous gas consecutive to a complicated diverticulitis: a case report and literature review. Int J Surg Case Rep 2016;23:186-9.

6. Nevins EJ, Moori P, Ward CS, Murphy K, Elmes CE, Taylor JV. A rare case of ischaemic pneumatosis intestinalis and hepatic portal venous gas in an elderly patient with good outcome following conservative management. Int J Surg Case Rep 2016;25:167-70.

7. Okada S, Azuma T, Kawashita Y, Matsuo S, Eguchi S. Clinical evaluation of hepatic portal venous gas after abdominal surgery. Case Rep Gastroenterol 2016;10:99-107. 